\title{
Modification and Inactivation of Human Ceruloplasmin by Oxidized DOPA
}

\author{
Jung Hoon Kang \\ Department of Genetic Engineering, Cheongin Universitv, Cheongin 360-764, Korea \\ Received December 20, 2003
}

\begin{abstract}
Ceruloplasmin (CP). the blue oxidase present in all vertebrates, is the major copper-containing protein of plasma. It has been proposed that oxidation of L-3.4-dihydroxyphenylalanine (DOPA) ntay contribute to the pathogenesis of neurodegenerative disorders. The effect of the oxidized products of DOPA on the modification of human CP was investigated. When CP was incubated with the oxidized L-DOPA, the protein was induced to be aggregated and ferroxidase activity was decreased in a time-dependent mamer. Radical scavengers and catalase significantly inhibited the oxidized DOPA-mediated CP aggregation. Copper chelatrors, Diethylenetriaminepenta acetic acid (DTPA) and Diethyldithiocarbanic acid (DDC), also inhibited the oxidative modification of CP. The results suggested that DOPA oxidation led to the formation of free radical and induced the $\mathrm{CP}$ aggregation.
\end{abstract}

Key Words : Ceruloplasmin. DOPA. Oxidation. Free radical

\section{Introduction}

Ceruloplasmin (CP) is an important protein that circulates in plasma as a major copper transport protein and contains greater than $95 \%$ of copper found in serum. The protein is a $\alpha-2$ glycoprotein. which is synthesized in hepatocytes and is secreted into the plasma with six atoms of tightly bound copper/molecule. ${ }^{1}$ The functions of $\mathrm{CP}$ are copper transporter. iron metabolism. antioxidant defense. tissue angiogenesis. and coagulation. $=-5$ It has been reported that $\mathrm{CP}$ catalyzed the oxidation of $\mathrm{Fe}$ (II) to $\mathrm{Fe}$ (III). the catalytic cycle involving four of the six copper associated with $\mathrm{CP}$ employs dioxygen as the terminal electron acceptor without the intermediacy of partially reduced oxygen species such as $\mathrm{O}_{2}{ }^{-}$or $\mathrm{H}_{2} \mathrm{O}_{2}{ }^{6.7}$ This oxidase activity increases during inflammation. infection. and injury. suggesting that serum $\mathrm{CP}$ acts possibly as an antioxidant and as an acute phase protein. ${ }^{8.9}$ Several functional activities of CP can be inactivated by exposure to a flux of oxygen free radicals generated by the hypoxanthine/xanthine oxidase system. ${ }^{10}$ During exposure to oxidative stress. it has been implicated that substantial CP inactivation may occur and free copper ions could be released. ${ }^{11-13}$ Therefore. damaged CP may cause the augmentation of free radical-mediated damage to other macromolecules upon exposure to oxidative stress.

Oxygen-free radicals were associated with pathogenic processes in neurodegenerative disorders. such as Parkinson's Disease (PD) and Alzheimer's Disease (AD). Faults with the respiratory chain and dopamine metabolism have also been theorized to contribute to free radical production. ${ }^{1+}$ Catechols are hydroquinones that may undergo oxidation to electrophilic semiquinones and quinines. It has been proposed that the quinone-mediated reactions beside polymerization may contribute to neurodegeneration in $\mathrm{PD}$. e.g. cataly tic transfer of reducing equivalents to molecular oxygen (redox cycling)

\footnotetext{
Tel: +82-43-229-8562; Fax: +82-43-229-8432; e-mail: jhlkang àchongiu.ac.kr
}

and adduction to macromolecules. ${ }^{15} \mathrm{~L}-\mathrm{DOPA}$ and dopamine can generate semiquinones. $\mathrm{O}_{2}^{-}$and $\mathrm{H}_{2} \mathrm{O}_{2}{ }^{16}$ in the presence of transition-metal ions. Iron and copper are able to generate $\mathrm{OH}$ through non-enzymatic reaction. Fenton reaction. ${ }^{17.18}$ $\mathrm{OH}$ is the most powerful oxidizing species among several reactive oxygen radicals. and is able to oxidize most macromolecules. The oxidation of cellular proteins has been described under many pathological conditions. ${ }^{19-22}$

In the present study: the effect of the non-enzymatically oxidized L-DOPA on the modification of CP was investigated. The results revealed that the aggregation of $\mathrm{CP}$ was induced by the products of oxidized DOPA via the generation of free radicals. Present results suggest that the oxidation of DOPA may be involved in the oxidative stressinduced aggregation of C.P in neurodegenerative disorders.

\section{Materials and Methods}

Materials. Sodium azide. mannitol. Dihydorxypheny'lalanine (DOPA), dopamine and catalase were purchased from Sigma (St. Louis. MO. USA). Chelex 100 resin (sodium form) was obtained from Bio-Rad (Hercules. CA. USA). All solutions were treated with Chelex 100 resin to remove traces of transition metal ions.

Protein oxidation. Protein concentration was determined by the method of Smith et al. ${ }^{23}$ and Aln et al ${ }^{24}$ Oxidation of CP was carried out by incubation of the enzyme $(0.2 \mathrm{mg} /$ $\mathrm{mL})$ in $10 \mathrm{mM}$ potassium phosphate buffer $(\mathrm{pH} 7.4)$ both in the presence or absence of $1 \mathrm{mM}$ DOPA at $37^{\circ} \mathrm{C}$. After incubation of the reaction mixtures. the mixtures were then placed into Ultrafree-MC filter and centrifuged at 13,000 $\mathrm{rpm}$ for $\mathrm{l} \mathrm{h}$ to remove DOPA. The mixture was then washed with Chelex 100 treated water and centrifuged for $l \mathrm{~h}$ at same speed to further remove DOPA. This was repeated four times. The filtrate was dried by freeze drier and dissolved with phosphate buffer.

Measurement of ferroxidase activity. The ferroxidase of $\mathrm{CP}$ was measured by the method of Sunderman and 
Nomoto. ${ }^{25} \mathrm{CP}(0.2 \mathrm{mg} / \mathrm{mL})$ was incubated in $0.1 \mathrm{M}$ sodium acetate buffer $(\mathrm{pH} 5.7)$ containing $500 \mu \mathrm{g} / \mathrm{mL}$, of $p$-phenylenediamine for $1 \mathrm{~h}$ at $37^{\circ} \mathrm{C}$ and the absorption was measured at $540 \mathrm{~nm}$.

Analysis of CP aggregation. After treatment with various concentrations of DOPA for various periods of time, samples of the reaction mixtures were diluted with a concentrated sample buffer $(0.25 \mathrm{M}$ Tris, $40 \%$ glycerol, $0.01 \%$ bromophenol blue). An aliquot of each sample was subjected to native PAGF as described by Laemmli, ${ }^{26}$ using a $10 \%$ acrylamide slab gel. The gels were stained with $0.15 \%$ Coomassie Brilliant Blue R-250.

Measurement of hydroxyl radical. Detection of hydroxyl radicals was determined by measuring thiobarbituric acid reactive 2-deoxy-D-ribose oxidation products. ${ }^{27}$ Reaction mixtures contained various concentrations of DOPA in the absence or presence of $10 \mu \mathrm{M} \mathrm{Cu}{ }^{2+}$. Mixtures were incubated at $37^{\circ} \mathrm{C}$ for $24 \mathrm{~h}$. The degradation of 2-deoxy-D-

(A)

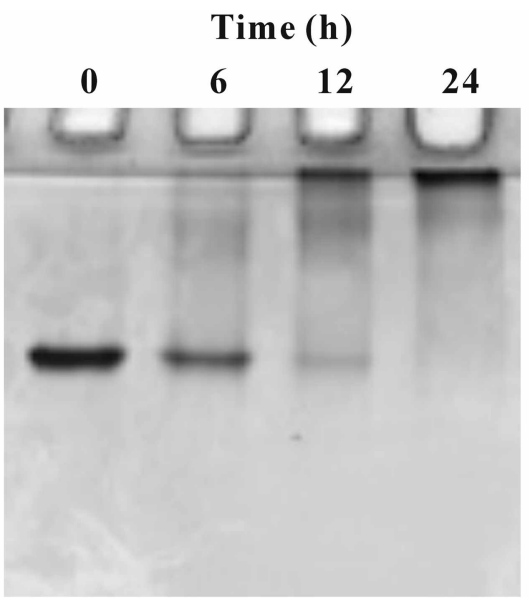

(B)

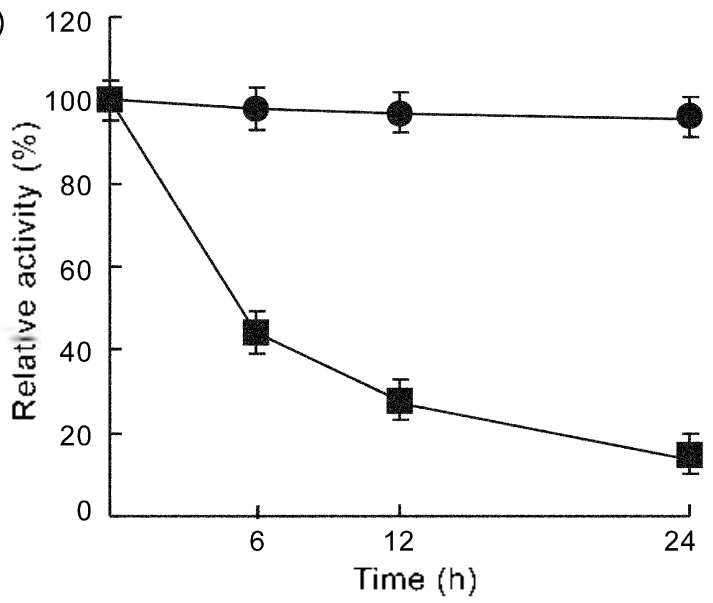

Figure 1. Modilication and inativation of $\mathrm{CP}$ alter the incubation with LOPA. (A) CP was incubated with I mM DOPA in $10 \mathrm{mM}$ potassium phosphate buffer $(\mathrm{pH} 7.4)$ at 37 " $\mathrm{C}$. for various incubation periods. Reactions were stopped at the time indicated by freering at $-80^{\circ} \mathrm{C}$ and an alicpot was analyzed by native PAGl.. (B) $\mathrm{CP}(0.2 \mathrm{mg} / \mathrm{mL})$ was incubated with ( $\boldsymbol{\square})$ or without $(\boldsymbol{e}) \mathrm{I} \mathrm{mM}$ DOPA in $10 \mathrm{mM}$ potassium phosphate buffer $(\mathrm{pH} 7.4)$ at $37^{\circ} \mathrm{C}$ for various incubation periods and the ferroxidase activity was measured by using $p$-pheylenediamine. 1)ata represent the means $\perp$ S.D. $(n=5)$ ribose was measured by adding $200 \mu \mathrm{L}$. of PBS, $200 \mu \mathrm{L}$. of $2.8 \%(\mathrm{w} / \mathrm{v})$ trichloroacetic acid, $200 \mu \mathrm{l}$. of $1 \%(\mathrm{w} / \mathrm{v})$ thiobarbituric acid, followed by heating at $100{ }^{\circ} \mathrm{C}$ for 10 min. After cooling, the absorbance at $532 \mathrm{~nm}$ was measured by UV/Vis spectrophotometer (Shimadzu, UV-1601).

\section{Results}

Since free radicals can be generated in autoxidation of catecholamines, ${ }^{16.18}$ the effect of DOPA on the CP modification was investigated. When $C P$ was incubated with 1 $\mathrm{mM}$ DOPA at $37^{\circ} \mathrm{C}$, the frequency of the protein aggregation increased in a time-dependent manner (Fig. 1A). During the incubation of $C P$ with DOPA, ferroxidase

\section{DOPA ( $\mathrm{mM})$}

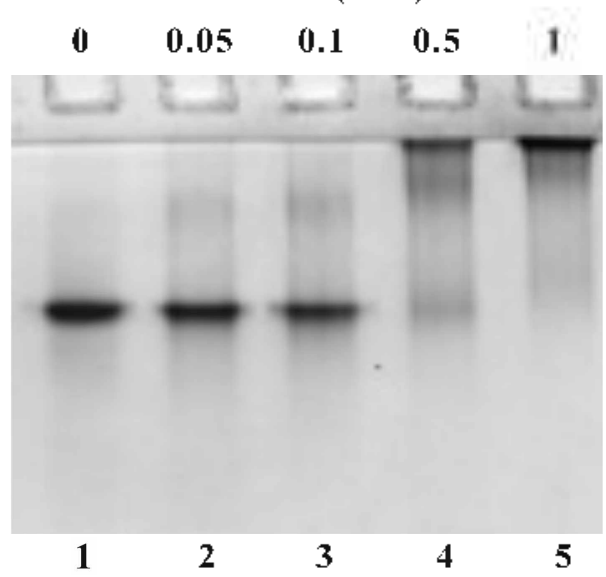

Figure 2, I:ltect of $\mathrm{DOPA}$ concentrations on modilication of $\mathrm{CP}$. $(P(0.2 \mathrm{mg} / \mathrm{mL}$ ) was incubated in $10 \mathrm{mM}$ phosphate bufter (pll 7.4 ) at $37^{\circ} \mathrm{C}$ for $24 \mathrm{~h}$ under various concentrations of DOPA. Lanc 1. CP control: lane 2-5. with 0.05. 0.1. 0.5 and I mM [JOPA.

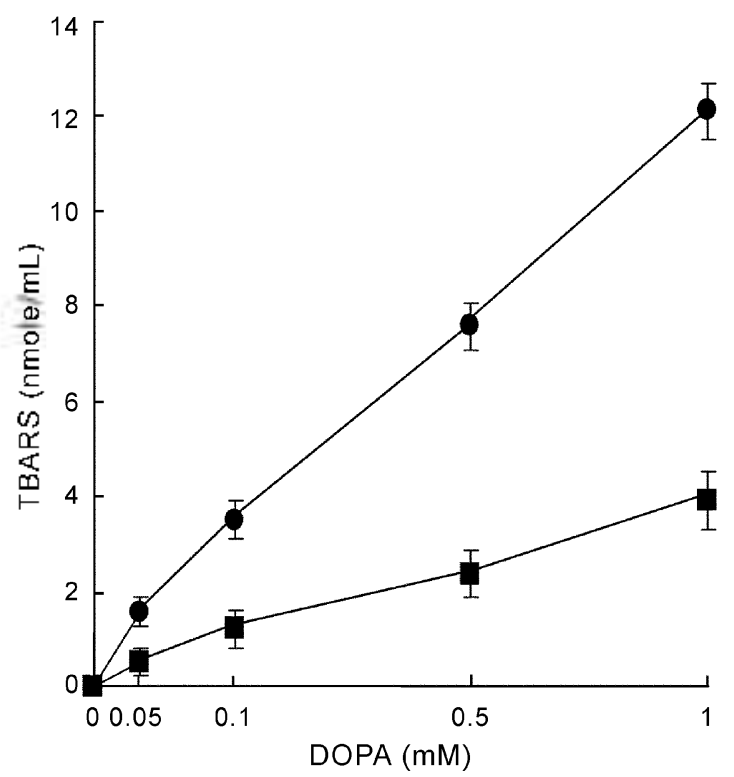

Figure 3. Generation of hydroxyl radical during the oxidation reaction of ISOPA. The reaction mixtures contained $10 \mathrm{m.M} 2$ deoxy-1)-ribose and various concentrations of DOPA without ( $a$ ) or with $100 \mathrm{uM} \mathrm{CuSO}$ ( e ) in $10 \mathrm{mM}$ phosphate butficr at $\mathrm{pH} 7.4$. 


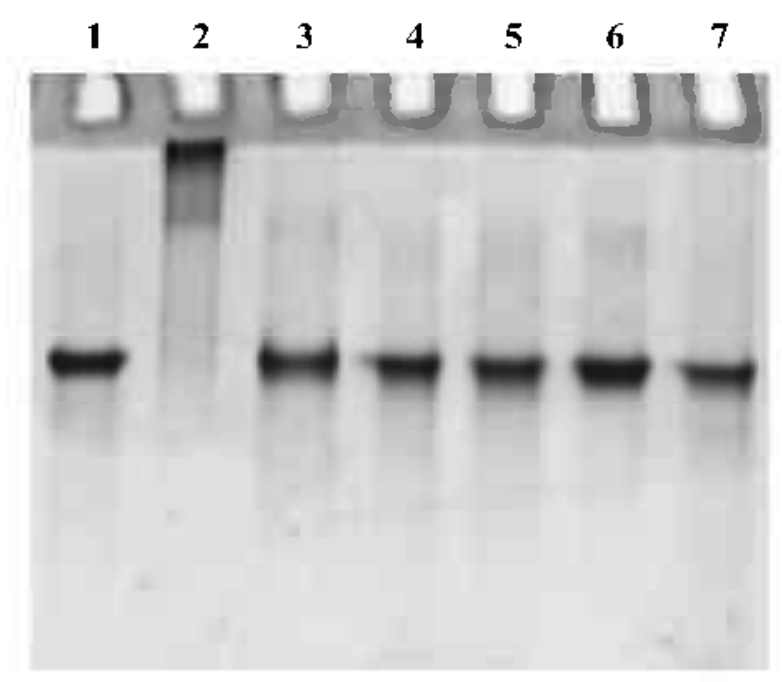

Figure 4. I:lfect of radical scavengers. calalise and copper chelators on the aggegation of CP by oxidized DOPA. CP $(0.2 \mathrm{mg} /$ $\mathrm{mL}$ ) was incubated with $1 \mathrm{mM}$ DOPA in $10 \mathrm{mM}$ phosphate buffer $(\mathrm{pH} 7.4)$ at $37{ }^{\circ} \mathrm{C}$, or $24 \mathrm{~h}$ in the presence of radical scavengers and copper chelators. I ane 1. CP control: lane 2. no addition ol effectors; lane $3.200 \mathrm{~m}$ M azide; lane $4.200 \mathrm{mM}$ mannitol; lane 5 . catalase (0.2 me/mL); lane 6. $10 \mathrm{mM}$ DTPA: lane $7.10 \mathrm{mM} D D C$.

activity was gradually decreased as a function of time (Fig. 1B). The results suggest that the protein aggregation by DOPA is associated with the inactivation of ferroxidase activity of CP. The aggregation of CP became apparent at $500 \mu \mathrm{M}$ DOPA; the aggregation increased up to $1 \mathrm{mM}$ DOPA (Fig. 2).

The participation of hydroxyl radical in the aggregation of CP by the oxidized DOPA was investigated. It has been shown that the reaction of hydroxyl radical with deoxyribose causes formation of a product that reacts with thiobarbituric acid to produce a chromogen. Thus the generation of hydroxyl radicals in the oxidation of DOPA was measured with thiobarbituric acid-reactive substance (TBARS). When 2-deoxy-D-ribose was incubated with various concentrations of DOPA in the presence of $\mathrm{Cu}^{2+}$, the rate of TBARS formation was increased up to 12.1 nmole. However, in the absence of $\mathrm{Cu}^{2-}$, the maximum rate of l'BARS formation was 3.9 nmole (Fig. 3). The aggregation of CP was significantly suppressed in the presence of azide, mannitol and catalase (Fig. 4, lane 3-5). These results suggest that the autoxidation of DOPA may lead to the generation of hydrogen peroxide and produce hydroxyl radical via transitional metal-catalyzed reaction (Fenton reaction). Evidence that copper chelators, DT'PA and DDC protected the CP against oxidized DOPA supported this mechanism (tig. 4, lane 6 and 7). Thus, hydroxyl radical might play a critical role in the aggregation of CP by the oxidized DOPA.

\section{Discussion}

The present study investigated the potential role of DOPA in the modification of CP. The toxicity of catechol may be augmented by its free radical-generating function in neuro- degenerative disorders. Since the level of free radicals was reported to be increased in the patients of neurodegenerative disorders, such as Parkinson's Disease (PD) and Alzheimer's Disease (AD) ${ }^{28.2^{24}}$ the oxidative modification of CP by free radicals might have pathological significance. The present results showed that modification of $C P$ was induced by the autoxidation of DOPA. L-DOPA and dopamine can oxidize in vitro to generate semiquinones, $\mathrm{O}_{2}^{-}$and $\mathrm{H}_{2} \mathrm{O}_{2}{ }^{16}$ a process greatly facilitated by the presence of transition-metal ions. In the case of iron and copper, $\mathrm{OH}$ will also be generated by Fenton reaction. ${ }^{18.27}$ In this study, the DOPA-mediated CP aggregation was inhibited by hydroxyl radical scavengers and catalase. These results indicate that hydroxyl radicals and hydrogen peroxide may involve in the aggregation of C.P.

Trace metal such as iron and copper, which are variously present in biological systems, may interact with active oxygen species, ionizing radiation, or microwave radiation to damage macromolecules. ${ }^{30-32}$ The cleavage of the metalloproteins by oxidative damage may lead to increases in the levels of metal jons in some biological cell. ${ }^{33}$ It has been reported that copper concentration was significantly increased in the cerebrospinal-fluid of $P D$ and AD patients. ${ }^{3 .+35}$ These results suggested that iron or copper-catalyzed oxidative reaction might contribute to the pathogenesis of neurodegenerative disorders. In the present study, copper ions led to enhancement of the hydroxyl radical formation. In addition to, copper chelators, DTPA and DDC, also inhibited DOPA-mediated CP aggregation. These results indicate that copper ions of $\mathrm{CP}$ maly contribute to DOPA-mediated $\mathrm{CP}$ aggregation.

In conclusion, the present results suggest that the modification of $C P$ was induced by the altoxidation of DOPA. involving $\mathrm{OH}$ generation from $\mathrm{H}_{2} \mathrm{O}_{2}$. Therefore, DOPAmediated CP modification might be involved in the pathogenesis of neurodegenerative disorders.

\section{References}

1. Takahashi. N.: Ottel. T. L.: Putnam. F. W. Proc. Natl Acad. Soi. (S.t 1984. 8/. 390-394.

2. Cioldstein, 1, M.: Kaplan, H. R,: Fdelson, II. S.: Weissmann, C. . . Biol. Chwm. 1979. 254.4040-4045.

3. Winge. D. R. Semin. Iner Dis. 1984. f. 239-251.

4. Folhman. J.: Klagsburn. M. Science 1987. 235. 442-447.

5. Walkar. F. J.: Fay. J. J. Biot (hem. 1990. 265. $1834-1836$.

6. Ryden. I, Coppe troteins and Copper Enewnes, lol. H/: 1984

7. Ciutteridge I. V. C. ('hem. Biol. Interuet. 1985, 56. 113-120.

8. Heming. R. J.: Whitman. I. P.: Gillin. I. D. Am. J. Ptysiol. 1991. 260. L68-L74.

9. Gitlius. J. D.J. Biof. Chem. 1988. 263.6281-6287.

10. Kim. I. G.: Park. S. Y.: Kim. K. C.: Yum. J. J. IFBS LeH. 1998. 43/. 473-475.

11. Chat M.-K.: Kim, 1.-I1, Biochemistry 1999, 38, I2104-12110.

12. Winyard. P.: I.unec. I.: Brailslord. S.: Blake. D. Int. J. Biochem. 1984. 16. $1273-1278$.

13. Winyard. I. G.: Hider. R. C.: Brailsford. S.: Drake. A. F.: Lunec. I: Blakc. D. R. Biochem. J. 1989. 258.435-445.

14. Jenner. P. Pathol. Biol. Paris, 1996, 4t. 57-64

15. Graham, D. (i.: Titfany, S. M.: Bell, W. R. Jr.: Guthnecht, W. C. 
Wol. Pharmacol. 1978. 14. 644-653

16. Pileblad. E.: Slivka. A.: Bratvold. D.: Cohen. G. Arch. Biochem. Biophys. 1988. 263. 447-452.

17. Halliwell. B.: Gutteridge. I. M. C. Free Radicals in Biology and Medicine Oxford: 1992.

18. Sutton. H. C.: Winterbourn. C. C. Free Radic. Biol. Med. 1989. 6. $53-60$.

19. Ames. B. N.: Shigenaga. M. K.: Hagen. T. M. Proc. Natl Acad. Sci. LSA 1993, $90,7915-7922$

20. Halliwell. B.: Gutteridge, J. M. Mol. Aspects. Med. 1985, 8. 89193.

21. Berlett. B. S.: Stadtman. E. R. J. Biol. Chem. 1997. 272. 2031320316.

22. Lee. K.: Cho. Y: Ueom. J.: Na. S.: Park. J. E.: Jo. I.: Kang. J. Bull. Eorean Chent. Soc. 2001. 22,1175-1176.

23. Smith, P. K. Krohn. R. I: Hermanson. G. T.: Mallia, A. K. Gartner. F.-H.: Provenzano, M. D.: Fujimoto, E. K.: Goeke, N. M. Olson. B. J.: Klenk. D. C. Anal. Biochem. 1985 150.76-85.

24. Ahn. S.-Y.: Jeon. S.-H.: Park. H.-J: Kong. K.-H. Bull. Koream Chem. Soc. 2003. 24. 1188-1192.
25. Sunderman1. F. W. Jr.: Nomoto. S. Clin. Chem. 1970. 16. $903-$ 910

26. Laemmli. U. K. Notwe $1970,227,6801-685$.

27. Halliwell, B.; Gutteridge, J. M. C. FEBS Lett, 1992, 307. 108112.

28. Ilic. T.: Jovanovic. M.: Joricic. A.: Tomovic. M. Iojnosanti. Pregl. 1998. 55. $463-468$.

29. Ilic. T.: Jovanovic. M.: Tovicic. A.: Tomovic. M Funct. Newal 1999. $1+1+141-147$.

30. Imlay, J. A.: Chin, S. M.: Linn. S. Science 1988, 240.640-642.

31. Sagripanti, J. L.; Kraemer, K. H. J. Biol. Chem. 1989. 264. 17291734.

32. Sagripanti. J. L.: Swicord. M. L.: Davis. C. C. Radiat. Res. 1987. 110. $219-231$.

33. O'Connell. M. J.: Peters. T. J. Chem. Phws Lipids 1987. 45. 241249.

34. Pall, H. S:- Williams. A. C.: Blake. D. R.: Lunec J.; Gutteridge J. M.: Hall. M.: Taylor. A. Lancet. 1987. 2. 238-241.

35. Multhaup. G.: Schlichsupp. A.: Hesse. L.: Behler. D.: Ruppert. T.: Masters. C. L.: Beyreuther. K. Science 1996. 271. 1406-1409. 